\title{
Medical school gift restriction policies and physician prescribing of newly marketed psychotropic medications: difference-in-differences analysis
}

\author{
(c) $(1)$ (8)
}

\author{
Marissa King assistant professor of organizational behavior ${ }^{1}$, Connor Essick research assistant ${ }^{1}$, \\ Peter Bearman Jonathan Cole professor of the social sciences ${ }^{2}$, Joseph S Ross assistant professor \\ of medicine ${ }^{3}$
}

${ }^{1}$ Yale University School of Management, New Haven, CT, USA; ${ }^{2}$ Interdisciplinary Center for Innovative Theories and Empirics, Columbia University, New York, NY 10027, USA ; ${ }^{3}$ Section of General Internal Medicine, Department of Medicine, Yale University School of Medicine, New Haven, CT, USA

\begin{abstract}
Objective To examine the effect of attending a medical school with an active policy on restricting gifts from representatives of pharmaceutical and device industries on subsequent prescribing behavior.

Design Difference-in-differences approach.

Setting 14 US medical schools with an active gift restriction policy in place by 2004.

Participants Prescribing patterns in 2008 and 2009 of physicians attending one of the schools compared with physicians graduating from the same schools before the implementation of the policy, as well as a set of contemporary matched controls.

Main outcome measure Probability that a physician would prescribe a newly marketed medication over existing alternatives of three psychotropic classes: lisdexamfetamine among stimulants, paliperidone among antipsychotics, and desvenlafaxine among antidepressants.

None of these medications represented radical breakthroughs in their respective classes.

Results For two of the three medications examined, attending a medical school with an active gift restriction policy was associated with reduced prescribing of the newly marketed drug. Physicians who attended a medical school with an active conflict of interest policy were less likely to prescribe lisdexamfetamine over older stimulants (adjusted odds ratio $0.44,95 \%$ confidence interval 0.22 to $0.88 ; \mathrm{P}=0.02$ ) and paliperidone over older antipsychotics $(0.25,0.07$ to $0.85 ; \mathrm{P}=0.03)$. A significant effect was not observed for desvenlafaxine (1.54, 0.79 to $3.03 ; P=0.20)$. Among cohorts of students who had a longer exposure to the policy or were exposed to more stringent policies, prescribing rates were further reduced.
\end{abstract}

Conclusion Exposure to a gift restriction policy during medical school was associated with reduced prescribing of two out of three newly introduced psychotropic medications.

\section{Introduction}

In 2002 the American Medical Student Association established a PharmFree Campaign to advocate for evidence based, rather than marketing based, prescribing. As part of these efforts, the association released the first "PharmFree scorecard" in 2007, which graded US medical schools on the presence or absence of a policy regulating interactions between students and faculty and representatives of the pharmaceutical and medical device industries. Since the first PharmFree scorecard was adopted, the number of US medical schools with conflict of interest policies has grown exponentially and most now have policies restricting gifts. ${ }^{1}$ The American Medical Student Association's approach to advocating against conflicts of interest among physicians is distinctive for its focus on medical students and medical education. Several organizations have suggested codes of conduct for ethical behavior to establish standards to regulate physician-industry collaborations, including the American Medical Association, ${ }^{2}$ the American Association of Medical Colleges, ${ }^{3}$ and the Pharmaceutical Research and Manufacturers Association, ${ }^{45}$ but each predominantly focuses on interactions with practicing physicians or academic investigators.

Studies conducted before the PharmaFree Campaign found that most medical students were exposed to marketing efforts during their medical education. ${ }^{6}$ On average, students either received a gift or attended an industry sponsored event weekly. ${ }^{7}$ Exposure to marketing efforts by the pharmaceutical industry during 
medical school has been associated with favorable attitudes towards the pharmaceutical industry. ${ }^{67}$ Furthermore, marketing efforts have been shown to reduce the time to new drug adoption $^{8}$ and increase the probability that a physician will adopt a new drug. ${ }^{9}$ Research has found that educational interventions strongly influence students' attitudes toward pharmaceutical marketing ${ }^{10}{ }^{11}$ and are associated with increased support for policies banning interactions between representatives of pharmaceutical companies and students. ${ }^{11}$ Similarly, students attending a medical school with restrictive marketing policies tend to have less favorable attitudes about promotional items than their peers who were not exposed to a conflict of interest policy ${ }^{12}$ and are less likely to trust the advice they receive from representatives of pharmaceutical companies. ${ }^{13}$ Although research has found that educational interventions and conflict of interest policies are associated with increased skepticism about pharmaceutical marketing, the effect of medical school gift restriction polices on subsequent prescribing remains unknown.

We studied the impact of attending a medical school with a gift restriction policy on the adoption of new drugs. To see whether attending a medical school with a gift restriction policy affected prescribing of new drugs, we used a difference-in-differences design to examine the effect of attending a school that implemented a gift restriction policy by 2004 . Although such an examination represents an early evaluation of these policies because of the lag time between physician medical education and independent clinical practice, understanding whether these policies achieve their goal of limiting marketing influence is important given the rapid increase in the number of schools adopting such policies. Using data from IMS Health, which includes national prescribing data from retail pharmacies in the United States, we examined the adoption of new drugs in three classes of psychotropic medications.

\section{Methods}

We examined physician prescribing of newly introduced medications within the stimulant, antipsychotics, and antidepressant classes. Data on prescriptions for these three drug classes written between July 2008 and March 2009 were obtained from IMS Health's Lifelink LRX longitudinal prescription database. The database contains anonymous individual prescriptions from about 33000 retail pharmacies, independent pharmacies, and mass retailers. Over $60 \%$ of retail prescriptions in the United States are covered in the database. Compared with census data, IMS Health's database is geographically representative and representative by sex, age, and insurance coverage. We linked IMS Health's data on prescriptions to the American Medical Association's physician masterfile using a deidentified prescriber number on both datasets in order to categorized prescribers by specialty, year of graduation from medical school, and medical school from which the physician graduated. The physician masterfile is a comprehensive source of data on both members of the American Medical Association and non-members that contains information on roughly 1.4 million physicians, residents, and medical students. The primary variables of interest for this analysis from the masterfile, medical school attended and graduation year, are obtained from the medical schools themselves and are time invariant. ${ }^{14}$ Accordingly, the accuracy of these components of the database is less sensitive than other elements to requests for updates from the American Medical Association.

\section{Medical school gift restriction policies}

Using internet searches, as well as information contained in the Institute of Medicine as a profession's conflict of interest database and the American Medical Student Association's PharmFree scorecard, one investigator (CE) either determined the initial implementation date of the gift restriction policy for medical schools that had a policy or verified that the school did not have a policy in place by the end of our study period for $87 \%(119 / 133)$ of accredited medical schools in the United States. The Institute of Medicine's database contains over 700 conflict of interest policies from 125 academic medical centers. ${ }^{15}$ In developing its database, the organization first contacted academic medical centers directly requesting a written policy and then searched the websites of academic medical institutions for relevant policies. Response rates to using the Pharmfree scorecard, which was first published in 2007, were low in its initial years but had a $98 \%$ participation rate in $2012 .{ }^{1}$ The primary goal of the scorecard is to assess the strength of conflict of interest polices, but the scorecard also contains summaries of the policies, updates, and links to school's policies. Given the low participation rate for using the scorecard in early periods, it was primarily used for identifying schools that implemented restrictive policies in 2008. Both of these sources are regularly updated, which could have led us to omit schools that had revised their policy but did not include a revision date. However, given the legal nature of gift policies, revision dates are typically included on documents. After we had obtained the dates of policy implementation, a second investigator (MK) then verified the dates on the policies included in the study.

\section{Study groups}

We identified 14 medical schools with a policy that explicitly prohibited or restricted gifts as of 2004. A restrictive cut-off date of policy implementation by 2004 was necessary to allow for the average time required to complete postgraduate residency training after graduation from medical school for physicians to be eligible to independently prescribe medications by July 2008 , the beginning of our prescribing observation period. Many of the schools that had a policy in place by 2004 had adopted policies as a result of state laws or military restrictions governing gifts. The policies varied in strength from almost complete bans on gifts to much weaker and ambiguous restrictions. Of the schools identified with policies in place before $2004,79 \%$ (11/14) were identified through the Institute of Medicine's conflict of interest database, two additional schools (14\%) were obtained through the cooperation of authors of a 2009 study that surveyed the deans of medical schools and found that 10 schools had a conflict of interest policy in place in $2005,{ }^{7}$ and the final school was obtained through internet searches. The supplementary file contains a complete list of schools with additional details on implementation dates.

Next we identified two cohorts of physicians to permit comparisons among those who attended the same medical school before and after implementation of a gift policy. The first cohort included physicians that graduated two years before the policy was implemented and therefore were not exposed or affected since the policy was enacted after they had graduated. The second cohort graduated in 2003 or 2004, after implementation of the policy.

\section{Matched controls}

To account for changes in prescribing over time, we created a matched control sample composed of physicians who graduated from 20 different medical schools that adopted a policy 
restricting gifts in 2008. Of the schools identified, all were found -using information obtained from the American Medical Students Association PharmFree scorecard. These physicians were never exposed to the policy since they graduated before implementation. We used a matched design to randomly select control physicians based on year of graduation, specialty, and 10ths of prescribing volume.

\section{Main outcome measure}

To determine the effect of gift restriction policies during medical training on prescribing as physicians, we examined physicians' propensity to prescribe newly introduced and marketed psychotropic medications over older medications in the same class. During our study period, antipsychotics, antidepressants, and stimulants were among the top selling classes of medications, with US sales ranks of 1,5 , and 15 , respectively. ${ }^{16}$ Stimulants, antidepressants, and antipsychotics were also among the most promoted classes of medications. ${ }^{17}$ Given the importance of these three classes of medications to the pharmaceutical industry, we identified a newly marketed medication in each class for our study: lisdexamfetamine (Vyvanse; Shire, Wayne, PA) among stimulants, paliperidone (Invega; Janssen Pharmaceuticals, Titusville, NJ) among antipsychotics, and desvenlafaxine (Pristiq; Pfizer, New York, NY) among antidepressants. Lisdexamfetamine was introduced in March of 2007, paliperidone in December of 2006, and desvenlafaxine in February of 2008. Although the drugs examined in this study vary in their level of innovation, none represented radical breakthroughs in their class and all relied on mechanisms of action already available on the market. These medications were the only oral medications within the three classes of data that we had access to that were approved within our study period.

\section{Statistical analysis}

We used a difference-in-differences method to examine the effect of a gift restriction policy on physicians' subsequent propensity to prescribe a new drug. A difference-in-differences analysis is a quasi-experimental technique, which we used to compare prescribing patterns of physicians who attended a school with a gift restriction policy when the policy was in place with those of physicians who attended the same school before the policy was in place, as well as with the prescriptions written by the two matched control groups.

Using this design, we compared prescribing patterns using three sets of logistic regression models for each class. The dependent variable in all of the logistic regressions was whether the prescription was written for one of the three newly marketed medications. Firstly, we carried out multivariate logistic regression including a dummy variable that was equal to 1 if a physician attended a school with a policy during the period when the policy was in place, a time dummy set equal to 1 if the student graduated in 2003 or 2004, and school fixed effects, which allowed us to estimate the effect of exposure to the policy on the odds that a physician will prescribe a newly introduced medication. In addition, the models accounted for method of prescription payment (Medicaid, third party, or cash), sex and specialty of the physician, and the physician's total number of in-class prescriptions. All models incorporated clustered standard errors to adjust for the clustering of observations within physicians, as well as school fixed effects. The school fixed effects capture any non-time varying differences between schools, including those that might influence whether or not a school adopted a policy.
The two additional sets of models test whether duration of exposure to the policy or the strength of the policy were associated with stronger policy effects. In one set of models, we included only students graduating from a school that had adopted a policy by 2002 in the policy group. Students attending these nine schools would have at minimum been exposed to the policy for at least half of their graduate education. In an additional set of models we included only graduates of 11 schools that had clear monetary limits on gifts in the policy group.

\section{Results}

Overall, 7.8\% (10 234/13 1342) of stimulant prescriptions were written for lisdexamfetamine, 1.3\% (1081/82 420) of antipsychotic prescriptions were written for paliperidone, and $0.5 \%(2686 / 574554)$ of antidepressant prescriptions were written for desvenlafaxine. In total, 27.8\% (681/2449) of prescribers wrote at least one prescription for lisdexamfetamine, $8.7 \%(102 / 1172)$ at least one prescription for paliperidone, and $6.9 \%(345 / 4981)$ at least one prescription for desvenlafaxine. Table $1 \Downarrow$ summarizes the characteristics of the physicians in our study. There were compositional differences between schools that adopted gift restriction policies before 2004 and later adopters, as well as between cohorts, in specialty composition and methods of payment.

\section{Stimulant prescribing—lisdexamfetamine}

Physicians who were exposed to a gift restriction policy during medical school were significantly less likely than non-exposed physicians to prescribe lisdexamfetamine over older stimulants. Of prescriptions written by physicians who attended a medical school with an active gift restriction policy, $5.9 \%(95 \%$ confidence interval $5.6 \%$ to $6.3 \%$ ) were for lisdexamfetamine, in contrast with $7.4 \%$ (7.1\% to $7.6 \%$ ) among physicians not exposed to a policy who graduated from the same school before the policy was implemented. Among matched controls attending a school that implemented a policy in $2008,8.3 \%$ (8.1\% to $8.6 \%)$ and $9.1 \%$ ( $8.7 \%$ to $9.4 \%)$ of prescriptions were for lisdexamfetamine among earlier and later graduates, respectively. Differences between these groups were significant $(\mathrm{P} \leq 0.001)$.

Using a difference-in-differences approach showed that attending a medical school with an active conflict of interest policy significantly reduced the odds that a physician would prescribe lisdexamfetamine, the newly introduced stimulant, over older stimulants (adjusted odds ratio $0.44,95 \%$ confidence interval 0.22 to $0.88 ; \mathrm{P}=0.02$; table $2 \Downarrow$ ). In the analysis examining the duration of the policy and its strength, a further reduction occurred in physicians' propensity to prescribe lisdexamfetamine. For physicians who attended a medical school in which they would have been exposed to a policy for longer than the group exposed to the policy in our main analysis, the odds of prescribing lisdexamfetamine was further reduced (adjusted odds ratio 0.21, 0.09 to $0.51 ; \mathrm{P}=0.001$; table $3 \Downarrow$ ). Attending a school with a strong active policy also reduced the odds of prescribing lisdexamfetamine (adjusted odds ratio 0.40 , 0.18 to 0.88 ; $\mathrm{P}=0.02$; table $4 \Downarrow$ ), which is slightly smaller than the odds ratio reported in the main analysis.

\section{Antipsychotic prescribing-paliperidone}

Physicians who were exposed to a gift restriction policy during medical school were significantly less likely than non-exposed physicians to prescribe paliperidone over older antipsychotics. Of prescriptions written by physicians who attended a medical 
school with an active gift restriction policy, $0.5 \%(95 \%$ confidence interval $0.4 \%$ to $0.7 \%$ ) were for paliperidone, in contrast with $1.7 \%$ (1.6\% to $2.0 \%$ ) among physicians who were not exposed to the policy and graduated from the same school. Among matched controls attending a school that implemented a policy in $2008,1.2 \%(1.1 \%$ to $1.3 \%)$ and $1.4 \%$ (1.1\% to $1.6 \%)$ of prescriptions were for paliperidone among the earlier and later cohorts, respectively. Differences between these groups were significant $(\mathrm{P} \leq 0.001)$.

Using a difference-in-differences approach, attending a medical school with an active conflict of interest policy was associated with a significantly decreased odds of prescribing paliperidone, the newly introduced antipsychotic (adjusted odds ratio 0.25 , $95 \%$ confidence interval 0.07 to $0.85 ; \mathrm{P}=0.03$; table 2 ). The odds ratios for the analyses examining the duration and strength of the policy were slightly lower, with an odds ratio of 0.20 ( 0.04 to $0.96 ; \mathrm{P}=0.05$; table 3 ) in the analysis of duration and 0.21 ( 0.06 to $0.72 ; \mathrm{P}=0.01$; table 4 ) in the models examining policy strength.

\section{Antidepressant prescribing-desvenlafaxine}

Exposure to a gift restriction policy during medical school was not associated with differential prescribing of desvenlafaxine. In all three models using a difference-in-differences approach, attending a medical school with an active gift restriction policy was not associated with significantly decreased odds of prescribing desvenlafaxine, the newly introduced antidepressant. In the main model, the odds ratio for students exposed to an active conflict of interest policy was 1.54 (95\% confidence interval 0.79 to $3.03 ; \mathrm{P}=0.20$; table 2). Results were also insignificant in models examining students who were exposed to the policy for a longer duration (adjusted odds ratio 0.82 , $95 \%$ confidence interval 0.35 to $1.92 ; \mathrm{P}=0.64$; table 3 ) or were exposed to a stricter policy (1.00, 0.47 to $2.12 ; \mathrm{P}=0.98$; table $4)$. The results of each of the three analyses for desvenlafaxine were largely driven by the relatively high level of prescribing among physicians in the early cohort of the matched control group compared with the other groups.

\section{Discussion}

Implementation of a policy to restrict the receipt of gifts from the pharmaceutical industry at US medical schools was associated with significantly reduced prescribing of two out of three newly marketed psychotropic medications among students once they reached clinical practice. The odds of prescribing a newly marketed stimulant and a newly introduced antipsychotic medication were reduced among physicians who graduated from a medical school that had an active gift restriction policy. The propensity to prescribe these two newly introduced medications was further reduced if the students were exposed to the policy for a longer duration or if the policy was relatively stringent. Our findings suggest that conflict of interest policies, which have been increasingly adopted by medical schools since $2002,{ }^{1}$ may have the potential to substantially impact clinical practice and reduce prescribing of newly marketed pharmaceuticals.

\section{Limitations of the study}

Our study has several limitations. Firstly, we were able to examine only schools that adopted a policy before 2004 to allow adequate time for physicians to complete residency and begin independent prescribing. To the extent that schools adopting policies before 2004 are different than schools adopting policies later, our results may differ. However, since our results include school fixed effects, this helps assuage concerns that the differences we observed may be due to differences between schools that implemented gift restriction policies by either 2004 or 2008 , rather than the policy itself, since the school fixed effects absorb any non-time varying differences between the schools. In addition, many of the schools included in our analysis adopted policies because of state or military regulations, rather than as a result of internal school dynamics. While this helps mitigate concerns about selection bias in the policy population, the choice to adopt a policy, rather than having it imposed on schools, may generate different results.

As an early analysis of the effect of gift restriction policies, our focus was limited to the impact of gift restriction policies enacted by medical schools by 2004 . These were among the first policies established among US medical schools. These early policies were typically more limited in scope and less stringent than policies normally implemented by schools in recent years. ${ }^{1}$ Many of the schools in our analysis have subsequently adopted more stringent policies, which makes our analysis a strong test of the effect of gift restriction policies. One critical question that our analysis cannot disentangle is whether the effect on prescribing we observed is due to the policy itself or to educational efforts that may have accompanied the implementation of the policy. In our analysis that examined the strength of the policy we found slightly stronger effects for more stringent policies, suggesting that educational efforts surrounding policy implementation may also be important. Based on a large body of social science research, which has found that even small gifts can have a substantial impact on behavior, ${ }^{18}$ we expect that more restrictive policies may have a greater impact on prescribing of newly marketed medications. Future research examining differences in prescribing behavior among physicians exposed to policies that completely ban gifts compared with limiting the size of gifts would help shed light on this important topic. Similarly, disentangling whether the effects of policies are moderated by the educational efforts that accompany their implementation will require future research.

Another potential limitation, common to retrospective analyses of policy, is that our analysis may not have captured all early adopters. This is particularly true if a policy was revised but the date of the revision was not included on the more recent policy. In addition, we were unable to examine the role that residency plays in moderating the effect of exposure to a gift restriction policy in medical school. If physicians attending schools with gift restriction policies disproportionately attend residency programs that also maintain gift restriction policies, this could make disentangling the effects we observe difficult. However, there is substantial heterogeneity among students within medical school classes and a great number of residency programs, mitigating our concerns. Finally, we were unable to assess the effect of gift restriction policies on medical school faculty since our data do not provide information on current institutional affiliations.

Our analyses were also limited to prescribing of three newly marketed psychotropic medications since we did not have data on other classes of medications. We cannot be certain that the same associations would have been observed for prescribing of other medication classes. Given that each of the three medications we examined are a reformulation of a product on the market, we did not have the ability to examine how these policies might affect the adoption of medications that are clear improvements over existing alternatives. 


\section{Conclusion}

Our study provides some early preliminary evidence that exposure to a gift restriction policy during medical school may reduce the likelihood that a physician will prescribe newly introduced medications over older alternatives within the same drug class. In instances where the newly introduced medication is a noticeable improvement over alternatives, such an effect could slow the diffusion of medical advances. In instances where the newly introduced medication offers no additional benefit to patients, such an effect may limit the unnecessary use of newer, more expensive brand name medications, potentially slowing the escalation of healthcare costs. Future research examining the effect of these policies on medications with varying levels of innovativeness is necessary to establish whether medical school gift restriction policies reduce prescribing of all newly marketed medications or affect prescribing selectively.

The statements, findings, conclusions, views, and opinions contained and expressed in this article are based in part on data obtained under license from IMS Health information services: Xponent database (2005-09) IMS Health. All Rights Reserved. In the tables the authors' calculations are based on data from IMS LifeLink Information Assets-LRX Longitudinal Prescripton Database, 2008-09, IMS Health. The statements, findings, conclusions, views, and opinions contained and expressed herein are not necessarily those of IMS Health or any of its affiliated or subsidiary entities.

Contributors: MK and JSR conceived and designed the study and drafted the manuscript. All authors participated in the analysis and interpretation of the data and critically revised the manuscript for important intellectual content. CE, MK, and PB obtained the data. MK conducted the statistical analysis. MK accepts full responsibility for the work, had access to the data, and controlled the decision to publish. She is guarantor.

Funding: MK and PB received support from the National Institute of Mental Health. JSR is currently supported by the National Institute on Aging (K08 AG032886) and by the American Federation of Aging Research through the Paul B Beeson Career Development Award Program. PB is currently supported by the NIH director's pioneer award program, part of the NIH Roadmap for Medical Research (grant No 1 DP1 OD003635-01). None of the funders had a role in study design, in the collection, analysis, and interpretation of data, in the writing of the report, or in the decision to submit the article for publication.

Competing interests: All authors have completed the ICMJE uniform disclosure form at www.icmje.org/coi_disclosure.pdf (available on request from the corresponding author) and declare: no support from any organization for the submitted work; no financial relationships with any organizations that might have an interest in the submitted work in the previous three years; JSR receives support from the Centers of Medicare and Medicaid Services to develop and maintain performance measures that are used for public reporting, receives grant support from
Medtronic, receives grant support from the Pew Charitable Trusts (which developed and continues to support the AMSA PharmFree scorecard), and is a member of a scientific advisory board for FAIR Health, a not for profit organisation with the mission to achieve fairness and transparency in healthcare reimbursement.

Ethical approval: This study was deemed exempt by Yale University's institutional review board.

Data sharing: Owing to the nature of our data license, data sharing is not possible.

1 American Medical Student Association. Executive summary 2012. www.amsascorecard. org/executive-summary.

2 American Medical Association. Gifts to physicians from industry. Council on Ethical and Judicial Affairs, American Medical Association; March 2008. www.ama-assn.org/ama/ pub/category/4001.html.

3 Association of American Medical Colleges. Industry funding of medical education. Association of American Medical Colleges, 2008.

4 Advanced Medical Technology Association. Code of ethics on interactions with health care professionals. 2008. www.advamed.org/NR/rdonlyres/61D30455-F7E9-4081-B21912D6CE347585/0/AdvaMedCodeofEthicsRevisedandRestatedEffective20090701.pdf.

5 Pharmaceutical Research and Manufacturers of America. Code on interactions with healthcare professionals. Pharmaceutical Research and Manufacturers of America, 2008. www.phrma.org/files/PhRMA\%20Marketing\%20Code\%202008.pdf.

6 Austad KE, Avorn J, Kesselheim AS. Medical students' exposure to and attitudes about the pharmaceutical industry: a systematic review. PLoS Med 2011;8:e1001037.

7 Sierles FS, Brodkey AC, Cleary LM, McCurdy FA, Mintz M, Frank J, et al. Medical students exposure to and attitudes about drug company interactions. JAMA 2005;294:1034-42.

8 Manchanda $\mathrm{P}, \mathrm{Xie} \mathrm{Y}$, Youn $\mathrm{N}$. The role of targeted communication and contagion in product adoption. Mark Sci 2008;27:961-76.

9 Greving JP, Denig P, van der Veen WJ, Beltman FW, Sturkenboom MCJM, Haaijer-Ruskamp FM. Determinants for the adoption of angiotensin II receptor blockers by general practitioners. Soc Sci Med 2006:63:2890-8.

10 Fugh-Berman AJ, Scialli AR, Bell AM. Why lunch matters: assessing physicians' perceptions about industry relationships. J Contin Educ Health Prof 2010;30:197-204.

11 Kao A, Braddock C, Clay M, Elliott D, Epstein S, Filstead W, et al. Effect of educational interventions and medical school policies on medical students' attitudes toward pharmaceutical marketing practices: a multi-institutional study. Acad Med 2011;86:1454-62.

12 Grande D, Frosch DL, Perkins A, Kahn BE. Effect of exposure to small pharmaceutical promotional items on treatment preferences. Arch Intern Med 2009;169:887-93.

13 McCormick B, Tomlinson G, Brill-Edwards P, Detsky A. Effect of restricting contact between pharmaceutical company representatives and internal medicine residents on posttraining attitudes and behavior. JAMA 2001;286:1994-9.

14 American Medical Association. AMA physcian masterfile. 2012. www.ama-assn.org/ama/ pub/about-ama/physician-data-resources/physician-masterfile.page?

15 Institute of Medicine as a Profession. Academic medical centers and conflict of interest. 2012. www.imapny.org/conflicts_of_interest/conflicts-of-interest-overview/amcs.

16 IMS National Sales Perspectives. 2008 U.S. sales and prescription information: top therapuetic classes by U.S. sales. 2008. www.imshealth.com/deployedfiles/ims/Global/ Content/Corporate/Press\%20Room/Top-line\%20Market\%20Data/2008\%20Top-line\% 20Market\%20Data/2008_Top_Therapy_Classes_by_U.S._Sales.pdf.

17 Vermont Attorney General. Pharmacuetical marketing disclosures: report of the Attorney General William H Sorrell. 2010. www.atg.state.vt.us/assets/files/FY09\%20Final\% 20Pharma\%20Disclosure\%20Report.pdf.

18 Dana J, Loewenstein G. A social science perspective on gifts to physicians from industry. JAMA 2010;290:252-5.

Accepted: 31 December 2012

\section{Cite this as: BMJ 2013;346:f264}

This is an open-access article distributed under the terms of the Creative Commons Attribution Non-commercial License, which permits use, distribution, and reproduction in any medium, provided the original work is properly cited, the use is non commercial and is otherwise in compliance with the license. See: $\mathrm{http}: / /$ creativecommons.org/licenses/bync/2.0/ and http://creativecommons.org/licenses/by-nc/2.0/legalcode. 


\section{What is already known on this topic}

Medical school policies restricting gifts to physicians from the pharmaceutical industry are becoming increasingly common The effect of such policies on physician prescribing behavior after graduation into clinical practice is unknown

\section{What this study adds}

For two of the three medications examined, attending a medical school with an active gift restriction policy was associated with reduced prescribing of the newly marketed drug

Among cohorts of students who had a longer exposure to the gift restriction policies or were exposed to more stringent policies, prescribing rates were further reduced

\section{Tables}

Table 1 | Characteristics of physicians and prescriptions by categorization of school and class of medication. Values are percentages (numbers) unless stated otherwise

\begin{tabular}{|c|c|c|c|c|c|c|c|c|c|c|c|c|}
\hline \multirow[b]{3}{*}{ Characteristics } & \multicolumn{4}{|c|}{ Stimulant (lisdexamfetamine) } & \multicolumn{4}{|c|}{ Antipsychotic (paliperidone) } & \multicolumn{4}{|c|}{ Antidepressant (desvenlafaxine) } \\
\hline & \multicolumn{2}{|c|}{ Policy before 2004} & \multicolumn{2}{|c|}{$\begin{array}{l}\text { Matched } \\
\text { controls }\end{array}$} & \multicolumn{2}{|c|}{ Policy before 2004} & \multicolumn{2}{|c|}{$\begin{array}{l}\text { Matched } \\
\text { controls }\end{array}$} & \multicolumn{2}{|c|}{ Policy before 2004} & \multicolumn{2}{|c|}{$\begin{array}{l}\text { Matched } \\
\text { controls }\end{array}$} \\
\hline & $\begin{array}{l}\text { Early } \\
\text { cohort }\end{array}$ & $\begin{array}{c}\text { Later } \\
\text { cohort/exposed } \\
\text { to policy }\end{array}$ & $\begin{array}{l}\text { Early } \\
\text { cohort }\end{array}$ & $\begin{array}{l}\text { Later } \\
\text { cohort }\end{array}$ & $\begin{array}{l}\text { Early } \\
\text { cohort }\end{array}$ & $\begin{array}{c}\text { Later } \\
\text { cohort/exposed } \\
\text { to policy }\end{array}$ & $\begin{array}{l}\text { Early } \\
\text { cohort }\end{array}$ & $\begin{array}{l}\text { Later } \\
\text { cohort }\end{array}$ & $\begin{array}{l}\text { Early } \\
\text { cohort }\end{array}$ & $\begin{array}{c}\text { Later } \\
\text { cohort/exposed } \\
\text { to policy }\end{array}$ & $\begin{array}{l}\text { Early } \\
\text { cohort }\end{array}$ & $\begin{array}{l}\text { Later } \\
\text { cohort }\end{array}$ \\
\hline $\begin{array}{l}\text { Mean graduation } \\
\text { year }\end{array}$ & 1998.2 & 2003.5 & 1998.1 & 2003.5 & 1998.3 & 2003.5 & 1998.2 & 2003.4 & 1998.0 & 2003.5 & 1998.1 & 2003.4 \\
\hline No of physicians & 736 & 539 & 706 & 468 & 505 & 344 & 207 & 116 & 1485 & 1124 & 1381 & 991 \\
\hline \multicolumn{13}{|l|}{$\begin{array}{l}\text { Specialty of } \\
\text { physicians: }\end{array}$} \\
\hline $\begin{array}{l}\text { General } \\
\text { medicine }\end{array}$ & $\begin{array}{l}45.7 \\
(336) \\
\end{array}$ & $38.4(207)$ & $\begin{array}{l}47.6 \\
(336)\end{array}$ & $\begin{array}{l}44.9 \\
(210)\end{array}$ & $\begin{array}{l}55.8 \\
(282) \\
\end{array}$ & $45.6(157)$ & $\begin{array}{l}58.0 \\
(120) \\
\end{array}$ & $\begin{array}{l}44.8 \\
(52) \\
\end{array}$ & $\begin{array}{c}50.2 \\
(745) \\
\end{array}$ & $51.4(578)$ & $\begin{array}{l}54.0 \\
(746)\end{array}$ & $\begin{array}{l}56.3 \\
(558) \\
\end{array}$ \\
\hline Pediatrics & $\begin{array}{l}23.2 \\
(171) \\
\end{array}$ & $18.9(102)$ & $\begin{array}{c}23.4 \\
(165)\end{array}$ & $\begin{array}{l}20.5 \\
(96) \\
\end{array}$ & $\begin{array}{l}13.3 \\
(67) \\
\end{array}$ & $8.4(29)$ & $5.8(12)$ & $4.3(5)$ & $\begin{array}{c}9.2 \\
(136) \\
\end{array}$ & $7.4(83)$ & $\begin{array}{c}9.8 \\
(135)\end{array}$ & $8.8(87)$ \\
\hline Psychiatry & $\begin{array}{l}10.3 \\
(76) \\
\end{array}$ & $21.0(113)$ & $9.6(68)$ & $\begin{array}{l}16.0 \\
(75) \\
\end{array}$ & $\begin{array}{l}15.0 \\
(76) \\
\end{array}$ & $32.6(112)$ & $\begin{array}{l}23.7 \\
(49) \\
\end{array}$ & $\begin{array}{l}36.2 \\
(42) \\
\end{array}$ & $6.3(93)$ & $12.8(144)$ & $6.3(87)$ & $\begin{array}{c}13.4 \\
(133) \\
\end{array}$ \\
\hline Other & $\begin{array}{l}20.8 \\
(153) \\
\end{array}$ & $21.7(117)$ & $\begin{array}{c}19.4 \\
(137)\end{array}$ & $\begin{array}{l}18.6 \\
(87) \\
\end{array}$ & $\begin{array}{l}15.9 \\
(80) \\
\end{array}$ & $13.4(46)$ & $\begin{array}{l}12.5 \\
(26)\end{array}$ & $\begin{array}{l}14.7 \\
(17) \\
\end{array}$ & $\begin{array}{l}34.6 \\
(511) \\
\end{array}$ & $28.7(319)$ & $\begin{array}{l}29.9 \\
(413) \\
\end{array}$ & $\begin{array}{l}21.5 \\
(213)\end{array}$ \\
\hline $\begin{array}{l}\text { No of } \\
\text { prescriptions }\end{array}$ & 45881 & 18437 & 43681 & 23343 & 25514 & 12021 & 35401 & 9484 & 25514 & 12021 & 35401 & 9484 \\
\hline \multicolumn{13}{|l|}{$\begin{array}{l}\text { Payment method } \\
\text { for prescriptions: }\end{array}$} \\
\hline Third party & $\begin{array}{c}71.9 \\
(32 \\
972) \\
\end{array}$ & $72.1(13291)$ & $\begin{array}{c}81.4 \\
(33 \\
546) \\
\end{array}$ & $\begin{array}{c}77.7 \\
(18 \\
127) \\
\end{array}$ & $\begin{array}{c}67.3 \\
(17 \\
160) \\
\end{array}$ & $63.6(7649)$ & $\begin{array}{c}66.8 \\
(23 \\
655) \\
\end{array}$ & $\begin{array}{c}76.2 \\
(7229)\end{array}$ & $\begin{array}{l}67.3 \\
(17 \\
160) \\
\end{array}$ & $63.6(7649)$ & $\begin{array}{l}66.8 \\
(23 \\
655) \\
\end{array}$ & $\begin{array}{c}76.2 \\
(7299)\end{array}$ \\
\hline Medicaid & $\begin{array}{l}23.0 \\
(10 \\
546) \\
\end{array}$ & $16.9(3118)$ & $\begin{array}{c}13.5 \\
(7891)\end{array}$ & $\begin{array}{c}16.7 \\
(3902)\end{array}$ & $\begin{array}{c}-28.6 \\
(7289)\end{array}$ & $30.3(3642)$ & $\begin{array}{c}29.5 \\
(10 \\
451)\end{array}$ & $\begin{array}{c}19.7 \\
(1864)\end{array}$ & $\begin{array}{cc}- & 28.6 \\
& (7289)\end{array}$ & $30.3(3642)$ & $\begin{array}{l}29.5 \\
(10 \\
451)\end{array}$ & $\begin{array}{c}19.7 \\
(1864)\end{array}$ \\
\hline Cash & $\begin{array}{c}5.2 \\
(2363)\end{array}$ & $11.0(2028)$ & $\begin{array}{c}5.1 \\
(2244)\end{array}$ & $\begin{array}{c}5.6 \\
(1314)\end{array}$ & $\begin{array}{c}-4.2 \\
(1065)\end{array}$ & $6.1(730)$ & $\begin{array}{c}3.7 \\
(1295)\end{array}$ & $\begin{array}{c}4.1 \\
(391)\end{array}$ & $\begin{array}{cc}- & 4.2 \\
(1065)\end{array}$ & $6.1(730)$ & $\begin{array}{c}3.7 \\
(1295)\end{array}$ & $\begin{array}{c}4.1 \\
(391)\end{array}$ \\
\hline
\end{tabular}


Table 2| Any US medical school with a policy on restriction of gifts from pharmaceutical industry before 2004

\begin{tabular}{|c|c|c|c|c|c|c|}
\hline \multirow[b]{2}{*}{ Variables } & \multicolumn{2}{|c|}{ Stimulant (lisdexamfetamine) } & \multicolumn{2}{|c|}{ Antipsychotic (paliperidone) } & \multicolumn{2}{|c|}{ Antidepressant (desvenlafaxine) } \\
\hline & Odds ratio $(95 \% \mathrm{Cl})$ & $P$ value & Odds ratio $(95 \% \mathrm{Cl})$ & $P$ value & Odds ratio $(95 \% \mathrm{Cl})$ & $P$ value \\
\hline Exposed to policy & $0.44(0.22$ to 0.88$)$ & 0.02 & $0.25(0.07$ to 0.85$)$ & 0.03 & 1.54 (0.79 to 3.03$)$ & 0.20 \\
\hline Period of exposure & 1.26 (0.96 to 1.66$)$ & 0.10 & $1.17(0.48$ to 2.89$)$ & 0.73 & $0.81(0.52$ to 1.26$)$ & 0.35 \\
\hline $\begin{array}{l}\text { Prescribing volume } \\
\text { (100s) }\end{array}$ & 1.05 (1.03 to 1.08$)$ & $<0.001$ & 1.04 (1.00 to 1.08$)$ & 0.03 & $1.02(1.00$ to 1.03$)$ & 0.10 \\
\hline Cash payment & 0.67 (0.55 to 0.81$)$ & $<0.001$ & 1.92 (1.24 to 2.97 ) & 0.003 & 0.94 (0.73 to 1.22$)$ & 0.66 \\
\hline Medicaid payment & 0.82 (0.66 to 1.02$)$ & 0.07 & 1.65 (1.09 to 2.50$)$ & 0.02 & $0.50(0.28$ to 0.90$)$ & 0.02 \\
\hline Psychiatry & $0.61(0.46$ to 0.80$)$ & 0.001 & 3.83 (1.18 to 12.4$)$ & 0.03 & 1.53 (0.77 to 3.06$)$ & 0.22 \\
\hline General medicine & 0.46 (0.35 to 0.59$)$ & $<0.001$ & 0.93 (0.26 to 3.36$)$ & 0.92 & 1.72 (0.94 to 3.12$)$ & 0.08 \\
\hline Male & $0.96(0.77$ to 1.18$)$ & 0.69 & 1.07 (0.53 to 2.13$)$ & 0.86 & 1.14 (0.83 to 1.57$)$ & 0.41 \\
\hline
\end{tabular}

Third party is the omitted insurance category. Other is the omitted provider specialty. All models include school fixed effects. Standard errors clustered by prescriber. 
Table 3| Any school with a policy for gift restriction from pharmaceutical industry before 2002

\begin{tabular}{|c|c|c|c|c|c|c|}
\hline \multirow[b]{2}{*}{ Variables } & \multicolumn{2}{|c|}{ Stimulant (lisdexamfetamine) } & \multicolumn{2}{|c|}{ Antipsychotic (paliperidone) } & \multicolumn{2}{|c|}{ Antidepressant (desvenlafaxine) } \\
\hline & Odds ratio $(95 \% \mathrm{Cl})$ & $P$ value & Odds ratio $(95 \% \mathrm{Cl})$ & $P$ value & Odds ratio $(95 \% \mathrm{Cl})$ & $P$ value \\
\hline Exposed to policy & $0.21(0.09$ to 0.51$)$ & 0.001 & $0.20(0.04$ to 0.96$)$ & 0.05 & 0.82 (0.35 to 1.92$)$ & 0.64 \\
\hline Period of exposure & $1.28(0.98$ to 1.69$)$ & 0.07 & $1.19(0.46$ to 3.08$)$ & 0.72 & 0.78 (0.51 to 1.22$)$ & 0.28 \\
\hline $\begin{array}{l}\text { Prescribing volume } \\
(100 \text { s) }\end{array}$ & $1.06(1.04$ to 1.09$)$ & $<0.001$ & $1.03(0.99$ to 1.07$)$ & 0.11 & 1.01 (0.99 to 1.03$)$ & 0.28 \\
\hline Cash payment & $0.70(0.57$ to 0.86$)$ & 0.001 & 1.89 (1.16 to 3.09$)$ & 0.01 & $0.93(0.71$ to 1.24$)$ & 0.64 \\
\hline Medicaid payment & 0.86 (0.68 to 1.09$)$ & 0.22 & $1.70(1.04$ to 2.78$)$ & 0.04 & 0.67 (0.36 to 1.22$)$ & 0.19 \\
\hline Psychiatry & 0.52 (0.38 to 0.72$)$ & $<0.001$ & 4.75 (1.33 to 16.9$)$ & 0.02 & $1.42(0.65$ to 3.10$)$ & 0.38 \\
\hline General medicine & $0.44(0.33$ to 0.58$)$ & $<0.001$ & $0.92(0.22$ to 3.88$)$ & 0.91 & $1.73(0.87$ to 3.43$)$ & 0.12 \\
\hline Male & $0.98(0.78$ to 1.24$)$ & 0.87 & $1.80(0.92$ to 3.50$)$ & 0.09 & $1.15(0.80$ to 1.64$)$ & 0.45 \\
\hline
\end{tabular}

All models include school fixed effects. Third party is omitted insurance category. Other is omitted provider specialty. Standard errors clustered by prescriber. 
Table 4 | Schools with strict policies on restriction of gifts from pharmaceutical industry

\begin{tabular}{|c|c|c|c|c|c|c|}
\hline \multirow[b]{2}{*}{ Variables } & \multicolumn{2}{|c|}{ Stimulant (lisdexamfetamine) } & \multicolumn{2}{|c|}{ Antipsychotic (paliperidone) } & \multicolumn{2}{|c|}{ Antidepressant (desvenlafaxine) } \\
\hline & Odds ratio $(95 \% \mathrm{Cl})$ & $P$ value & Odds ratio $(95 \% \mathrm{Cl})$ & $P$ value & Odds ratio $(95 \% \mathrm{Cl})$ & $P$ value \\
\hline Exposed to policy & $0.40(0.18$ to 0.88$)$ & 0.02 & 0.21 (0.06 to 0.72$)$ & 0.01 & $1.00(0.47$ to 2.12$)$ & 0.98 \\
\hline Period of exposure & $1.26(0.96$ to 1.66$)$ & 0.10 & $1.16(0.47$ to 2.85$)$ & 0.75 & $0.80(0.51$ to 1.24$)$ & 0.31 \\
\hline $\begin{array}{l}\text { Prescribing volume } \\
\text { (100s) }\end{array}$ & $1.06(1.03$ to 1.08$)$ & $<0.001$ & 1.05 (1.01 to 1.09$)$ & 0.03 & $1.01(0.99$ to 1.03$)$ & 0.21 \\
\hline Cash payment & $0.66(0.54$ to 0.80$)$ & $<0.001$ & $1.86(1.19$ to 2.90$)$ & 0.01 & $0.93(0.70$ to 1.22$)$ & 0.59 \\
\hline Medicaid payment & $0.79(0.62$ to 1.01$)$ & 0.06 & $1.60(1.09$ to 2.33$)$ & 0.02 & 0.51 (0.27 to 0.98$)$ & 0.04 \\
\hline Psychiatry & $0.57(0.42$ to 0.77$)$ & $<0.001$ & $4.21(1.11$ to 16.0$)$ & 0.04 & $1.46(0.70$ to 3.06$)$ & 0.32 \\
\hline General medicine & $0.47(0.35$ to 0.62$)$ & $<0.001$ & $1.12(0.26$ to 4.76$)$ & 0.88 & 1.55 (0.81 to 2.94$)$ & 0.18 \\
\hline Male & $0.94(0.75$ to 1.18$)$ & 0.59 & 0.91 (0.45 to 1.86$)$ & 0.81 & $1.22(0.86$ to 1.73$)$ & 0.27 \\
\hline
\end{tabular}

All models include school fixed effects. Third party is the omitted insurance category. Other is omitted provider specialty. Standard errors clustered by prescriber. 